\title{
Soroprevalência de herpesvírus bovino tipo 1 em fêmeas bovinas na microrregião do Vale do Rio dos Bois, Goiás, Brasil
}

\author{
Mírianny Urzêda $1^{*}$, Eduardo de Paula Nascente ${ }^{2}$, \\ Pedro Gonçalves Margon Ribeiro ${ }^{3}$, Rodrigo Diniz Castro ${ }^{3}$, \\ Weder Rener Espíndola ${ }^{2}$, Livia Carlos da Silva ${ }^{3}$, Wesley José de Souza 4
}

\begin{abstract}
RESUMO
A pecuária constitui uma das principais atividades econômicas contribuintes para o Produto Interno Bruto (PIB) brasileiro, exercendo papel fundamental no processo de uso e ocupação de terras no Brasil. Doenças infecciosas de origem bacteriana, viral ou parasitária podem afetar o sistema reprodutivo, tanto dos machos como das fêmeas, causando uma série de problemas de infertilidade nos rebanhos, com diferentes níveis de gravidade. Dentre as doenças mais importantes de origem viral que afetam a natureza reprodutiva e que já foram identificadas em bovinos no Brasil, destaca-se a Rinotraqueíte Infecciosa Bovina (IBR). O objetivo deste trabalho foi realizar um estudo epidemiológico no estado de Goiás, especificamente na Microrregião do Vale do Rio dos Bois (municípios de Cezarina, Mairipotaba e Pontalina), detectando a presença de anticorpos contra a IBR pelo teste de vírus-neutralização (VN). Das propriedades estudadas, foi encontrada uma soroprevalência de 96,4\% para anticorpos neutralizantes contra a IBR em fêmeas bovinas acima de 24 meses. Os resultados encontrados no presente estudo demonstraram que há uma elevada taxa de prevalência da infecção por BoHV-1 na Microrregião do Vale do Rio dos Bois. Os dados deste estudo poderão servir de base para se traçarem estratégias para o controle da doença, com orientação aos produtores.
\end{abstract}

Palavras-chave: Anticorpos, BoHV-1, Vírus, Vírus-neutralização.

$$
* * *
$$

\footnotetext{
${ }^{1}$ Instituto Federal Goiano - Câmpus Rio Verde, Rio Verde, Goiás, Brasil.

2 Departamento de Medicina Veterinária, Instituto Federal Goiano - Câmpus Urutaí, Urutaí, Goiás, Brasil.

${ }^{3}$ Médicos Veterinários Autônomos, Goiás, Brasil.

${ }^{4}$ Setor de Reprodução Animal, Departamento de Medicina Veterinária, Instituto Federal Goiano Câmpus Urutaí, Urutaí, Goiás, Brasil.

* Corresponding author: Rodovia Sul Goiana, Km 01, Zona Rural, Rio Verde, Goiás, Brasil. Email; miriannyurzeda@hotmail.com
} 


\section{Introdução}

A pecuária constitui uma das principais atividades econômicas contribuintes para o Produto Interno Bruto (PIB) brasileiro, exercendo papel fundamental no processo de uso e ocupação de terras do Brasil, assim como na alimentação da população (IBGE, 2013). A expansão dessa atividade no país é obtida por meio de programas de acasalamento dirigido através da monta natural, técnica de inseminação artificial e outras diversas técnicas biotecnológicas de reprodução, em consonância com o melhoramento genético (PEREIRA, 2008).

A saúde reprodutiva de machos e fêmeas utilizados nesses programas constitui fator decisivo para a obtenção de descendentes com bom desempenho produtivo e precocidade (PEREIRA, 2008). Doenças infecciosas de origem bacteriana, viral ou parasitária podem afetar o sistema reprodutivo dos animais, tanto dos machos como das fêmeas, causando uma série de problemas de infertilidade com diferentes níveis de gravidade, sendo que algumas dessas enfermidades podem ser transmitidas para os fetos ou recém-nascidos por via transplacentária ou transmamária (FLORES e WEIBLEN et al., 2016).

Dentre as doenças mais importantes que afetam a natureza reprodutiva de origem viral e que já foram identificadas em bovinos no Brasil, destaca-se a Rinotraqueíte Infecciosa Bovina (IBR). O Herpesvírus Bovino tipo 1 (BoHV-1) é o agente causador da Rinotraqueíte Infecciosa Bovina ou também chamada de Vulvovaginite Pustular Infecciosa Bovina (IBR/IPV) (ROIZMAN et al.,1995). As consequências mais severas são as falhas reprodutivas em decorrência de abortos e natimortalidade, podendo ser observado também rinotraqueíte, vulvovaginite pustular, mastite, balanopostite e conjuntivite (TAKIUCHI et al., 2005).

O estado de Goiás se destaca entre os estados com a maior produção de leite no Brasil, e a Microrregião do Vale do Rio dos Bois está entre as 
mais importantes produtoras do estado (LIMA, 2005). Alguns trabalhos conseguiram demonstrar a soroprevalência do BoHV-1 no rebanho do estado, como já relatado por Barbosa et al. (2005), Affonso et al. (2010), Anunciação et al. (1989), Silva (2014), mas nenhum específico na microrregião goiana em questão. Assim, o objetivo deste trabalho foi realizar sorologia para BoHV-1em fêmeas bovinas com problemas reprodutivos provenientes de propriedades de três cidades na Microrregião do Vale do Rio dos Bois, Goiás, Brasil.

\section{Material e métodos}

Foram coletadas amostras de sangue de 57 fêmeas bovinas, todas mestiças, com idade entre 24 e 54 meses, entre janeiro e fevereiro de 2015 . As propriedades foram escolhidas aleatoriamente dentre as que se inscreveram como propriedade parceira do projeto. Todas as propriedades selecionadas possuíam ao menos uma fêmea bovina que apresentava problemas reprodutivos, com destaque para os quadros de aborto. Dessa forma, foram selecionadas oito propriedades, distribuídas em três municípios (Cezarina, Mairipotaba e Pontalina) da Microrregião do Vale do Rio dos Bois, estado de Goiás, Brasil. Este trabalho foi aprovado pela Comissão de Ética no Uso de Animais do Instituto Federal Goiano sobre protocolo de número 022/2015.

Inicialmente, foi realizado um exame clínico completo dos animais para deteç̧ão dos possíveis sinais clínicos da infecção por herpesvírus, investigando-se: aumento de temperatura corporal, hiperemia de mucosa vulvovaginal, edema de vulva, presença de secreção na vagina, ulcerações e erosões na parede do trato respiratório, além de possíveis quadros de enterites, infecções bacterianas secundárias, aborto, infertilidade e distúrbios reprodutivos (FLORES e WEIBLEN et al., 2016). 
A pesquisa de anticorpos neutralizantes foi realizada pelo teste de vírus-neutralização (VN) (OIE, 2008), usando a estirpe Nebraska do BoHV1. Para isso, as amostras de sangue foram colhidas por punção da veia jugular externa ou da veia sacral média, utilizando-se tubos sem anticoagulante e sistema a vácuo (Vacunteiner Becton-Dickson ${ }^{\circledR}, \quad B D$ Worldwide Brasil). No momento da coleta, as amostras foram deixadas em repouso em temperatura ambiente para retração do coágulo, e em seguida foram transportadas sob refrigeração para o laboratório onde foram centrifugadas a $744 \mathrm{G}$ durante 10 minutos para separação do coágulo.

$\mathrm{O}$ soro foi separado em alíquotas de $1 \mathrm{~mL}$ em tubos tipo Eppendorf® de $1,5 \mathrm{~mL}$, e estocados em freezer à temperatura de $-20{ }^{\circ} \mathrm{C}$ até o momento da realização dos testes. Para serem testados, os tubos foram descongelados, sendo inativado o sistema complemento em banho-maria à temperatura de $56{ }^{\circ} \mathrm{C}$ durante 30 minutos, e colocados em duplicata nas microplacas de 96 cavidades. Foram utilizados em cada prova o controle do vírus e o controle de células Madin \& Darby Bovine Kidney (MDBK). A placa foi incubada em estufa à temperatura de $37{ }^{\circ} \mathrm{C}$ em atmosfera controlada com $5 \%$ de $\mathrm{CO} 2$. Após 96 horas, a placa foi observada em microscópio invertido, para avaliação dos efeitos citopáticos característicos do vírus (HENDRIX, 2005). O título viral foi calculado segundo o método descrito por Reed e Muenc (1938).

Um levantamento epidemiológico foi realizado com o intuito de avaliar potenciais fatores de risco de contágio e disseminação da doença. Os fatores avaliados incluíram o tipo de exploração (corte, leite ou mista), as condições de criação (extensiva, confinada ou semiconfinada), o tipo de ordenha (manual ou mecânica), o uso de inseminação artificial, a ocorrência de aborto, a presença de outros animais domésticos e/ou silvestres, a compra e venda de reprodutores, o aluguel de pasto, o uso de pasto em comum, a utilização de piquete para parto/pós-parto, a raça e a idade dos animais. 
Para a análise estatística, optou-se pelo método descritivo, compilando os dados de cada propriedade avaliada, permitindo-se inferir sobre as principais variações individuais e coletivas, sendo assim um método fidedigno para a observação dos aspectos epidemiológicos avaliados.

\section{Resultados e discussão}

Nas propriedades estudadas, encontrou-se uma soroprevalência de 96,4\% de anticorpos neutralizantes contra BoHV-1 como demonstrado na Tabela 1. Esses resultados são superiores aos encontrados por outros autores que realizaram um levantamento soroepidemiológico no estado de Goiás e encontraram uma soroprevalência de 84,5\% e 83\%, como demonstrado por Affonso et al. (2018) e Vieira et al. (2003), respectivamente.

Tabela 1 - Procedência das amostras de sangue bovino que foram utilizadas na avaliação dos efeitos citopáticos do herpesvírus bovino tipo 1, provenientes da Microrregião do Vale do Rio dos Bois, Goiás, Brasil.

\begin{tabular}{ccccc}
\hline Propriedade & Município & $\begin{array}{c}\text { Número de } \\
\text { animais }\end{array}$ & $\begin{array}{c}\text { Número de animais } \\
\text { positivos }\end{array}$ & $\begin{array}{c}\text { Frequência } \\
\text { relativa (\%) }\end{array}$ \\
\hline 1 & Mairipotaba & 9 & 8 & 88,89 \\
2 & Mairipotaba & 3 & 3 & 100 \\
3 & Mairipotaba & 4 & 4 & 100 \\
4 & Pontalina & 11 & 11 & 100 \\
5 & Pontalina & 6 & 6 & 100 \\
6 & Pontalina & 7 & 7 & 100 \\
7 & Cezarina & 9 & 9 & 87,5 \\
8 & Cezarina & 8 & 7 & 96,4 \\
\hline Total & - & 57 & 55 &
\end{tabular}

*As amostras foram consideradas reagentes a partir da diluição 1⁄2 (OIE, 2008).

Resultados semelhantes foram observados nas regiões Centro-Oeste e Sudeste do País, onde se tem intenso trânsito de animais. Rocha et al. (2001) chegaram à conclusão de que 91,9\% dos animais pesquisados em Minas Gerais eram soropositivos; já Tomich et al. (2009) encontraram soroprevalência de 50,9\% para BoHV-1 no Mato Grosso do Sul; e Quinteiro (2016) encontrou 21,2\% de animais machos disseminando Herpesvírus 
Bovino tipo-1 pelo sêmen (tendo sido analisados animais saudáveis) no Mato Grosso, o que evidencia a disseminação do BoHV-1 na região Centro Oeste.

Essa alta prevalência pode ser explicada pelo fato de a investigação epidemiológica neste trabalho ter sido realizada somente na Microrregião do Vale do Rio dos Bois, onde havia queixas de produtores rurais relativas à ocorrência de problemas reprodutivos, com elevada frequência de abortos. Além disso, nesta pesquisa, foram utilizadas apenas fêmeas bovinas com idade entre 24 e 54 meses, o que não ocorreu em outros trabalhos realizados em regiões distintas do estado de Goiás, onde foram utilizados animais de sexo e faixa etária diferentes.

Dentre as propriedades estudadas, $75 \%$ delas compravam os reprodutores utilizados em suas propriedades e $25 \%$ vendiam seus touros. Quanto ao manejo de pasto, a metade das propriedades alugava seus pastos para outros produtores rurais, enquanto a outra metade não utilizava pasto em comum, e $75 \%$ delas utilizavam a ordenha mecanizada. Na fase de parto e/ou pós-parto, todas as propriedades utilizavam piquete separado para fêmeas, porém todos os produtores afirmaram que a reprodução estava sendo realizada somente através de monta natural.

Os fatores de risco encontrados nas propriedades correlacionaram-se com a forma de disseminação dessa enfermidade, podendo esta ser direta, através de aerossóis, por contato entre animais infectados e susceptíveis (EENGELS e ACKERMANN, 1996); ou indireta, ocorrendo via água ou alimento contaminado, e principalmente pela via venérea, através do sêmen, e até mesmo pela ordenhadeira (EENGELS, 1996; DIAS et al.,2008). Bezerra et al. (2012) observaram fatores semelhantes a estes, acrescentando ainda a presença de diferentes animais de produção nas propriedades, como suínos, ovinos e caprinos, além da densidade dos bovinos no sistema de produção (BARBOSA et al., 2005).

Outro fator de risco presente nas propriedades é relativo ao modo como os novos animais eram introduzidos nas propriedades estudadas, ou 
seja, sem o atestado negativo para a doença em questão, problema esse encontrado em 75\% das propriedades. Esse resultado se assemelha aos resultados encontrados por Van Schaik et al. (1998) e Dias et al. (2008), que observaram que nas propriedades onde eram introduzidos novos animais sem atestado negativo para IBR eram detectadas maiores frequências de animais soropositivos. Rufino et al. (2006) afirmaram que a introdução de animais sem atestado negativo para BoHV-1 conduz à ineficiência de técnicas de melhoramento genético, como transferências de embriões, ocorrendo ainda a disseminação do agente entre animais saudáveis, como ressaltado por Meyer et al. (2003).

O maior índice de soropositividade foi detectado em fêmeas que abortavam principalmente no terço final da gestação. Das fêmeas avaliadas, $85 \%$ apresentavam essa sintomatologia, com ocorrência em todas as propriedades. Tal observação chamou a atenção pelo fato de as fêmeas bovinas apresentarem somente o abortamento como sintoma, uma vez que o vírus pode causar severas alterações respiratórias (MEYER, 2001), infecções genitais (KAHRS, 2001) e alterações reprodutivas, como repetições de cios e intervalos entre partos irregulares (STRAUB, 1991; BEZERRA et al., 2012).

Porém, Rufino et al. (2006) citaram a possibilidade da existência de animais assintomáticos no rebanho, como já demonstrado por Ackermann et al. (1982). Esses autores descreveram que a estratégia de latência do vírus por longo período possibilita que animais assintomáticos, ou que apresentem poucos sinais clínicos da doença, atuem como potenciais transmissores do agente (BARAN,2014).

Os animais avaliados eram oriundos de rebanhos leiteiros criados em sistemas de semiconfinamento, corroborando Bezerra et al. (2012), Boelaert et al. (2005) e Woodbine et al. (2009), observando que a disseminação desse agente acontece de forma mais rápida quando comparada com bovinos de corte, devido ao manejo frequente na ordenha e ao aumento de contato entre os animais. Da mesma maneira, Sousa et al. (2013) observaram que o 
método de criação dos animais favorece não só a transmissão, mas também o processo de instalação da infecção do vírus, tendo em vista que o sistema de criação semi-intensiva propicia a proximidade dos animais, facilitando o meio de transmissão do BoHV-1.

Os dados deste estudo poderão auxiliar nas estratégias de controle da doença, como o descarte gradual de animais positivos. É um método de controle indicado, uma vez que o animal, tendo sofrido infecção primária, torna-se portador do BoHV-1 por toda a sua vida, atuando daí em diante como potencial fonte de infecção para os suscetíveis (PITUCO et al., 1997). Porém, é necessário avaliar o custo/benefício dos programas de combate à doença tendo por base a situação epidemiológica do rebanho, pois só a partir desse ponto pode-se definir e adotar as medidas estratégicas mais apropriadas para controle e profilaxia da doença (PITUCO, 2009).

Assim, orientar os produtores da microrregião sobre a importância da vacinação é uma prática necessária, visto que a vacinação contra o IBR ainda é pouco difundida na região, considerando que todos os produtores participantes deste estudo relataram não realizar a imunização do rebanho contra doenças reprodutivas. Este trabalho será de fundamental importância para a conscientização dos médicos veterinários e dos produtores da região pesquisada e de outras regiões do estado de Goiás, no sentido da necessária percepção para que sejam feitas novas investigações epidemiológicas capazes de mapear a real situação do rebanho goiano diante da presença da IBR como uma doença letal e comprometedora da eficiência reprodutiva da pecuária leiteira.

\section{Conclusão}

Os resultados encontrados no presente estudo demonstraram que há uma elevada quantidade de animais positivos para BoHV-1 em propriedades dos municípios da Microrregião do Vale do Rio dos Bois, estado de Goiás, 
Brasil. Vale ressaltar que os dados encontrados foram observados em função da ocorrência de fatores de risco aos quais os animais da região estavam expostos, tais como a aquisição de animais positivos e a falta de vacinação contra IBR, havendo assim a necessidade de se implantar um correto manejo nas propriedades, com levantamentos soroepidemiológicos e vacinação de todas as fêmeas do rebanho, visando evitar a entrada e a disseminação do vírus nessa região e promover de forma indireta o desenvolvimento de manejos em outras regiões do estado de Goiás.

$$
* * *
$$

\title{
Seroprevalence of bovine herpesvirus type 1 in bovine females in the microregion of the Vale do Rio dos Bois, Goias, Brazil
}

\begin{abstract}
Livestock is one of the main activities of the gross domestic Product (GDP), exercising a fundamental role in the land use and occupation process in Brazil.. Infectious diseases, bacterial, viral or parasitic origin, may affect the reproductive system of both males and females, causing a series of problems of infertility with different levels of occurrence. One of the most important diseases that affect the reproductive sphere of viral origin and that have already been identified in cattle in Brazil the infectious bovine rhinotracheitis (IBR). The aim of this work was to carry out an epidemiological study in the State of Goiás, specifically in the Vale do Rio dos Bois microregion (municipalities of Cezarina, Mairipotaba and Pontalina), detecting the presence of antibodies to the IBR, by vírusneutralização (VN). The properties studied were found a seroprevalence of $96.4 \%$ for neutralizing antibodies against IBR in bovine females over 24 months. The results found in this study showed that there is a high prevalence of infection for BoHV-1 at Vale do Rio dos Bois microregion. The data for these studies can serve as a base to plot strategies for the control of the disease, with the guidance of producers Keywords: Antibodies, BoHV-1, Virus, Viral Neutralization.
\end{abstract}

\section{Referências}

ACKERMANN, M.; PETERHANS, E.; WYLER, R.DNA of bovine herpesvirus type 1 in the trigeminal ganglia of latently infected cal.es. American Journal of Veterinary Research, v.43, n.1, p.36-40, 1982. 
AFFONSO, I. B.; AMORIL, J.G.; ALEXANDRINO, B.; BUZINARO, M.G.; MEDEIROS, A.S.R.; SAMARA, S.I. Anticorpos contra o herpesvírus bovino tipo 1 (BoHV-1) nas dez regiões de planejamento do Estado de Goiás, Brasil. Ciência Animal Brasileira, v.11, n.4, p.892-898, 2010.

ANUNCIAÇÃO, A.V.M.; LEITE, R.C.; MOREIRA, E.C.; REIS, R. Presença de anticorpos para o herpesvírus bovino 1 (BHV-1) em bovinos nos estados de Minas gerais, Goiás e Rio de Janeiro através da prova de hemoaglutinação passiva. Arquivo Brasileiro de MedicinaVeterinária e Zootecnia, v.41, n.5, p.433-441, 1989.

BARAN, M.R. Avaliação da presença de herpesvírus bovino tipo $1 \mathrm{em}$ amostras de sêmen provenientes de touros jovens. 2014. 50 f. Tese (Mestrado em Saúde e Produção de Ruminantes). Universidade Norte do Paraná, Paraná, 2014.

BARBOSA, A.C.V.C.; BRITO, W.M.E.D.; ALFAIA, B.T. Soroprevalência e fatores de risco para a infecção pelo herpesvírus bovino tipo 1 (BoHV-1) no estado de Goiás, Brasil. Ciência Rural, v.35, n.6, p.1368-1373, 2005.

https://doi.org/10.1590/S0103-84782005000600022

BEZERRA, D.C.; CHAVES, N.P.; SOUSA, V.E.; SANTOS, H.P.; PEREIRA, H.M. Fatores de risco associados á infecção pelo herpesvírus bovino tipo 1 em rebanhos bovinos leiteiros da região amazônica maranhense. Arquivos do Instituto Biológico de São Paulo, v.79, n.1, p.107-111, 2012.

https://doi.org/10.1590/S1808-16572012000100016

BOELAERT, F.; SPEYBROECK, N.; KRUIF, A.; AERTS, M.; BURZYKOWSKI, T.; MOLENBERGHS, G.; BERKVENS, D.L. Riskfactors for bovine herpesvirus-1 seropositivity. PreventiveVeterinary Medicine, v.69, p.285-295, 2005.

DIAS, J.Á.; ALFIERI, A.A.; MÉDICI, K.C.; FREITAS, J.C.; FERREIRA, J.S.N.; MULLER, E.E. Fatores de risco associados à infecção pelo herpesvírus bovino 1 em rebanhos bovinos da região Oeste do Estado do Paraná. Pesquisa Veterinária Brasileira, v.28, n.3, p.161-168, 2008. 
EENGELS, M.; ACKERMANN, M. Pathogenesis of ruminant herpesvirus infections. Veterinary Microbiology,v.53, n.1, p.3-15, 1996. https://doi.org/10.1016/S0378-1135(96)01230-8

FLORES, E.F.; WEIBLEN, R. Herpesviroses de Bovinos. In: MEGID, J.; RIBEIRO, M.G.; PAES, A.C. Doenças infecciosas em animais de produção e de companhia. $1^{a}$ ed., Rio de Janeiro: Roca, 2016. Cap.65, p.708.

GOMES, R.C.; FEIJÓ, G.L.D.; CHIARI, L. Evolução e Qualidade da Pecuária Brasileira. Embrapa gado de corte, Nota Técnica, p.1-4, 2017. Disponível em: <https://www.embrapa.br/documents/10180/21470602/EvolucaoeQualidadePecuari a.pdf/64e8985a-5c7c-b83e-ba2d-168ffaa762ad>. Acesso em: 28 de abril de 2018.

HENRIX, C. M. Procedimentos laboratoriais para técnicos veterinários. $4^{\mathrm{a}}$ ed., São Paulo: Roca, 2005. 568p.

INSTITUTO BRASILEIRO DE GEOGRAFIA E ESTATÍSTICA (IBGE). Pesquisas trimestrais da pecuária. Manual Técnico, $4^{\mathrm{a}}$ ed., v.1, 2013. Disponível em: < https://biblioteca.ibge.gov.br/visualizacao/instrumentos de coleta/doc3558.pdf $>$. Acesso em: 23 de junho de 2018.

KAHRS, R.F. Infectious bovine rhinotracheitis and infectious pustularvulvovaginitis. In: KAHRS, R.F. Viral disease of catle. $2^{\mathrm{a}}$ ed. Ames: Iowa State University Press, 2001. p.159-170.

LIMA, W.M. Aindústria do Leiteem Goiás. Conjuntura Econômica Goiana. Goiânia, SEPLAN - Secretaria do Planejamento e Desenvolvimento. Boletim Trimestral, n.6, p.16-23, 2005.

MEYER, G.; LEMAIRE, M.; ROS, C.; BELAK, K.; GABRIEL, A.; CASSART, D.; COIGNOUL, F.; BELAK, S.; THIRY, E. Comparative pathogenesis of acute and latent infections of calves with bovineherpesvirus types 1 and 5 . Archives of Virology, v.146, n.4, p.633-652, 2001.

https://doi.org/10.1007/s007050170136 
MEYER, A.D.; COTEZ, A.; SOARES, R.M.; PITUCO, M.E.; OKUDA, L.; CASTRO, A.M.M.G.; RICHTZEINHAIN, L. J. Comparação das técnicas de isolamento viral e Nested PCR na detecção do BHV-1 em sêmen bovino experimentalmente e naturalmente contaminado. Arquivos do Instituto Biológico, v.70, n.2, p.143146, 2003.

WORLD ORGANIZATION FOR ANIMAL HEALTH. Manual of diagnostic tests and vaccines for terrestrial animals. $6^{\text {a }}$ ed. Paris: OIE, 2008. 784p. Disponívelem: <http://www.oie.int/doc/ged/D7709.PDF>. Acesso em: 01 de junho de 2018.

PEREIRA, J.C.C. Melhoramento Genético aplicado à produção animal. Fundação de Estudo e Pesquisa em Medicina Veterinária e Zootecnia Escola de Veterinária da UFMG, 2008.

PITUCO, E.M. Aspectos clínicos, prevenção e controle da IBR. Instituto Biológico - Secretária de Agricultura e Abastecimento de São Paulo, 2009. Disponível em: <http://www.infobibos.com/Artigos/2009_2/IBR/index.htm>. Acesso em: $13 / 06 / 2018$.

PITUCO, E.M.; STEFANO, E.; OKUDA, L.H.; PARAVENTI, R.; COELHO, P. V.; BILYNSKYJ, M.C.V.Modelo alternativo para erradicação da Rinotraqueite Infecciosa Bovina/Vulvovaginite Infecciosa (IBRIIPV) em rebanhos bovinos leiteiros. Arquivos do Instituto Biológico de São Paulo, v.64, n.17, p.29, 1997.

QUINTEIRO, R.C. Avaliação molecular da excreção do herpesvírus bovino tipo 1 (BoHV-1) no sêmen de touros do estado de Mato Grosso. Dissertação (Mestrado em Biociência Animal). 2016. 52f. Universidade de Cuiabá, MT, 2016.

REED, R.H.; MUENCH, H.A single method of estimating fifth percent end points. The American Journal of Hygiene, v.27, p.493-497, 1938. 
ROCHA, M.A.; GOUVEIA, Z.I.P.; LOBATO, R.C.; LEITE, R.C. Pesquisa de anticorpos para IBR em amostragem de demanda no Estado de Minas Gerais. Arquivo Brasileiro de Medicina Veterinária e Zootecnia, p.53, n.6, p.645$647,2011$.

ROIZMAN, B.; DESROSIERS, R.C.; FLECKENSTEIN, B.; LOPEZ, C.; MINSON, A.C.; STUDDERT, M.J.Family Herpesviridae. Archives of Virology, v.10, p.114-127, 1995.

RUFINO, F.A.; SENEDA M.M.; ALFIERI A.A. Impacto o herpesvírus bovino 1 e do vírus da diarreia viral bovina na transferência de embriões. Archives of Veterinary Science, v.11, n.1, p.78-84, 2006.

https://doi.org/10.5380/avs.v11i1.5606

SILVA, D. R. Deteç̧ão molecular de herpesvírus bovinos tipos 1 e 5 em amostras de encéfalos bovinos incluídas em parafina. 2014. 47f. Dissertação (Mestrado em Ciência Animal) - Universidade Federal de Goiás, Goiânia, GO, 2014.

SOUSA, V.E.; BEZERRA, D.C.; CHAVES, N.P.; SANTOS, H.P.; PEREIRA, H.M. Frequência de anticorpos e fatores de risco associados á infecção pelo vírus da diarreia viral bovina (BVDV) e herpesvírus bovino tipo 1 (BoHV-1) em fêmeas bovinas leiteiras criadas em sistema de produção semi-intensivo. Rev. Bras. Med. Vet., v.35, n.1, p.21-25, 2013.

STRAUB, O.V.C. BHV-1 Infectious: Relevance and spread in Europe. Compendium in Immunology, Microbiology and Infectious Diseases, v.14, n.2, p.175-186, 1991. https://doi.org/10.1016/0147-9571(91)90130-6

TAKIUCHI, E.; MÉDICI, K.C.;ALFIERI, A.F.; ALFIERI, A.A. Bovine herpesvirus type 1 abortions detected by a semi-nested PCR in Brazilian cattle herds. Veterinary Science, v.79. n.1, p.85-88, 2005.

https://doi.org/10.1016/j.rvsc.2004.11.005

TOMICH, R.G.P.; SERRA, C.V.; BOMFIM, M.R.Q.; CAMPOS, F.S.; LOBATO, Z.I.P.; PELLEGRIN, A.O.; PELLEGRIN, L.A.; BARBOSA-STANCIOLI, 
E.F.Sorodiagnóstico de doenças da reprodução em rebanhos de bovinos leiteiros de assentamentos rurais de Corumbá, MS. Arq. Bras. Med. Vet. Zootec., v.61, n.4, p.986-991, 2009.

VAN SCHAIK, G.; DIJKHUIZEN, A.A.; HUIRNE, R.B.M.; SCHUKKEN, Y.H.; NIELEN, M.; HAGE, J.J. Risk factors for existence of bovine herpesvirus 1 antibodies on nonvaccinating Dutch dairy farms. Preventive Veterinary Medicine, v.34, n.3, p.125-136, 1998.

VIEIRA, S.; BRITO, W.M.E.D.; SOUZA, W.J.; AALFAIA, B.T.; LINHARES, C.L. Anticorpos para o herpesvírus bovino 1 (BHV-1) em bovinos do Estado de Goiás. Ciência Animal Brasileira, v.4, n.2, p.131-137, 2003.

WOODBINE, K.A.; MEDLEY, G.F.; MOORE, S.J.; RAMIREZ-VILLAESCUSA, A.M.; MASON. S.; GREEN, L.E. A four longitudinal sero-epidemiological study of bovine herpesvirus type-1 (BHV-1) in adult cattle in 107 unvaccinated herds in south west England. BMC Veterinary Research, v.5, n.5, p.1-12, 2009. 